\title{
Inherited and acquired alterations in development of breast cancer
}

\author{
This article was published in the following Dove Press journal: \\ The Application of Clinical Genetics \\ II November 20 I I \\ Number of times this article has been viewed
}

\section{Piera Rizzolo \\ Valentina Silvestri \\ Mario Falchetti \\ Laura Ottini}

Department of Molecular

Medicine, "La Sapienza” University

of Rome, Rome, Italy
Correspondence: Laura Ottin Sapienza University of Rome, Department of Molecular Medicine, Viale Regina Elena 324,

Rome 0016I, Italy

Tel +390649973009

Fax +390649973004

Email laura.ottini@uniromal.it
Abstract: Breast cancer is the most common cancer among women, accounting for about $30 \%$ of all cancers. In contrast, breast cancer is a rare disease in men, accounting for less than $1 \%$ of all cancers. Up to $10 \%$ of all breast cancers are hereditary forms, caused by inherited germ-line mutations in "high-penetrance," "moderate-penetrance," and "low-penetrance" breast cancer susceptibility genes. The remaining $90 \%$ of breast cancers are due to acquired somatic genetic and epigenetic alterations. A heterogeneous set of somatic alterations, including mutations and gene amplification, are reported to be involved in the etiology of breast cancer. Promoter hypermethylation of genes involved in DNA repair and hormone-mediated cell signaling, as well as altered expression of micro RNAs predicted to regulate key breast cancer genes, play an equally important role as genetic factors in development of breast cancer. Elucidation of the inherited and acquired genetic and epigenetic alterations involved in breast cancer may not only clarify molecular pathways involved in the development and progression of breast cancer itself, but may also have an important clinical and therapeutic impact on improving the management of patients with the disease.

Keywords: breast cancer, inherited susceptibility, acquired alterations, epigenetics

\section{Introduction}

Breast cancer is currently the most common cancer among women, accounting for about $30 \%$ of all cancers. ${ }^{1}$ In contrast, breast cancer is a rare disease in men, accounting for less than $1 \%$ of all cancers. ${ }^{2}$ The age-specific incidence rates for breast cancer in women increase rapidly until the age of 50 years, and then increase at a slower rate for older women, while incidence rates for breast cancer in men increase linearly and steadily with age. Overall, current epidemiologic and pathologic data, such as age-frequency distribution, age-specific incidence rate patterns, and prognostic factor profiles, suggest that male breast cancer is similar to postmenopausal female breast cancer. ${ }^{2}$ It is generally accepted that breast cancer may represent the same disease entity in both genders, and common hormonal, genetic, and environmental risk factors are involved in the pathogenesis of breast cancer in women and men. Hormonal changes, such as increased estrogen exposure due to diabetes, obesity or liver disease, and environmental and lifestyle factors, such as carcinogen exposure or alcohol intake, are associated with risk of developing breast cancer. ${ }^{3}$ However, the major predisposition factor for breast cancer is a positive family history of the disease. Patients of both genders with a positive first-degree family history have a twofold increased risk, which increases to more than fivefold with the number of affected relatives and early onset relatives, thus suggesting a relevant genetic component in 
breast cancer risk. ${ }^{4}$ It is estimated that up to $10 \%$ of all breast cancers are hereditary forms, caused by inherited germ-line mutations in breast cancer susceptibility genes. Commonly, inherited mutations are loss-of-function mutations that occur in tumor suppressor genes involved in DNA repair and cell cycle checkpoint activation. ${ }^{1}$ The remaining $90 \%$ of breast cancers are due to acquired somatic, genetic, and epigenetic alterations. ${ }^{5}$ Genetic alterations include gain-of-function mutations, amplification, deletions, and rearrangements occurring in genes which stimulate cell growth, division, and survival. ${ }^{6}$ Epigenetic deregulation, mainly due to promoter methylation, may also contribute to the abnormal expression of these genes. ${ }^{7}$ In addition, the involvement of micro RNAs (miRNAs) in modulating gene expression in the development of breast cancer has been recently reported. ${ }^{8}$ The focus of this review will be on the most relevant inherited and acquired alterations in the development of breast cancer in both genders. We did a systematic literature search using PubMed to provide a synopsis of the current understanding and future directions of research in this field. We selected original articles and reviews published up to April 2011. The following search key terms were used to query the PubMed website: "inherited breast cancer," "breast cancer AND susceptibility," "breast cancer AND somatic alterations," "breast cancer AND epigenetic," "breast cancer AND miRNA." The abstracts resulting from these queries were individually analyzed for relevance.

\section{Inherited susceptibility to breast cancer}

To date, $5 \%-10 \%$ of all breast cancers are caused by inherited germ-line mutations in well identified breast cancer susceptibility genes. ${ }^{1}$ According to their mutation frequency and the magnitude of their impact in breast cancer susceptibility, these genes can be divided into "high-penetrance," "moderate-penetrance," and "low-penetrance" genes (Figure 1). ${ }^{9}$ Variants in the two major high-risk breast cancer genes, ie, $B R C A 1$ and $B R C A 2$, occur rarely in the population, but confer a high risk of breast cancer to the individual. ${ }^{1}$ P53 and PTEN, two genes involved in rare syndromes (Li-Fraumeni and Cowden syndromes, respectively), also confer a high risk of breast cancer. ${ }^{1}$ However, $P 53$ and PTEN germ-line mutations are very rare, and it is unlikely that these mutations would account for a proportion of breast cancers in the absence of their respective syndromes. ${ }^{10,11}$

Overall, high-risk genes account for about $25 \%$ of inherited breast cancers (Figure 1). ${ }^{12}$ Variants in genes function- ally related to $B R C A 1 / 2$ in DNA repair pathways confer an intermediate risk of breast cancer. These variants are rare, occurring in less than $1 \%$ of the population, and their contribution to the risk of breast cancer is less than $5 \%$ (Figure 1 ). ${ }^{13}$ Recently, a third class of low-penetrance susceptibility alleles has been identified. These alleles, which may occur in genic or nongenic regions, confer a lower risk but are very common in the population. ${ }^{13}$ Due to their low penetrance, the real contribution of these common variants to breast cancer risk is not entirely clear (Figure 1). Overall, this scenario suggests that the majority of genetic factors involved in breast cancer susceptibility are still unknown.

\section{High-penetrance breast cancer genes}

$B R C A 1$ and $B R C A 2$ are the most important breast cancer susceptibility genes in high-risk families (Table 1). BRCA1/2 mutations are considered to be responsible for approximately $30 \%$ of breast cancer cases with a family history of breast/ ovarian cancer, and it has been estimated that inherited $B R C A 1$ and BRCA2 mutations account for $5 \%-10 \%$ of the total percentage of breast cancer. ${ }^{14-16}$

In women, germ-line $B R C A 1$ and $B R C A 2$ mutations confer a high risk for developing breast cancer by age 70 years. Initial studies based on multiple-case families, reported a female breast cancer risk at age 70 years in $B R C A 1$ and BRCA2 mutation carriers of $85 \%$ and $84 \%$, respectively. ${ }^{17}$ Later meta-analyses showed that the average cumulative female breast cancer risk in BRCA1 mutation carriers by 70 years of age, unselected for family history, was $46 \%-65 \%$ and the corresponding estimates for $B R C A 2$ were $43 \%-45 \%{ }^{18,19}$

In male breast cancer cases, $B R C A 2$ mutations are much more common than $B R C A 1$. Mutations in the $B R C A 2$ gene are estimated to be responsible for $60 \%-76 \%$ of male breast cancers occurring in high-risk breast cancer families, whereas the BRCA1 mutation frequency ranges from $10 \%$ to $16 \%{ }^{17,20}$ In a large population-based male breast cancer series, we reported a mutation frequency of about $7 \%$ and $2 \%$ for $B R C A 2$ and $B R C A 1$, respectively. ${ }^{21}$ Interestingly, a founder effect was observed in BRCA1-associated male breast cancer cases. ${ }^{22}$

All known $B R C A 1 / 2$ mutations are recorded in the Breast Information Core database (http://www.nhgri.nih. gov/Intramural_research/Lab_transfer/Bic/). To date, 1643 distinct germ-line BRCA1 mutations and 2015 BRCA2 mutations have been reported in the database. The great majority of $B R C A 1 / 2$ mutations in breast cancer are predicted to truncate 


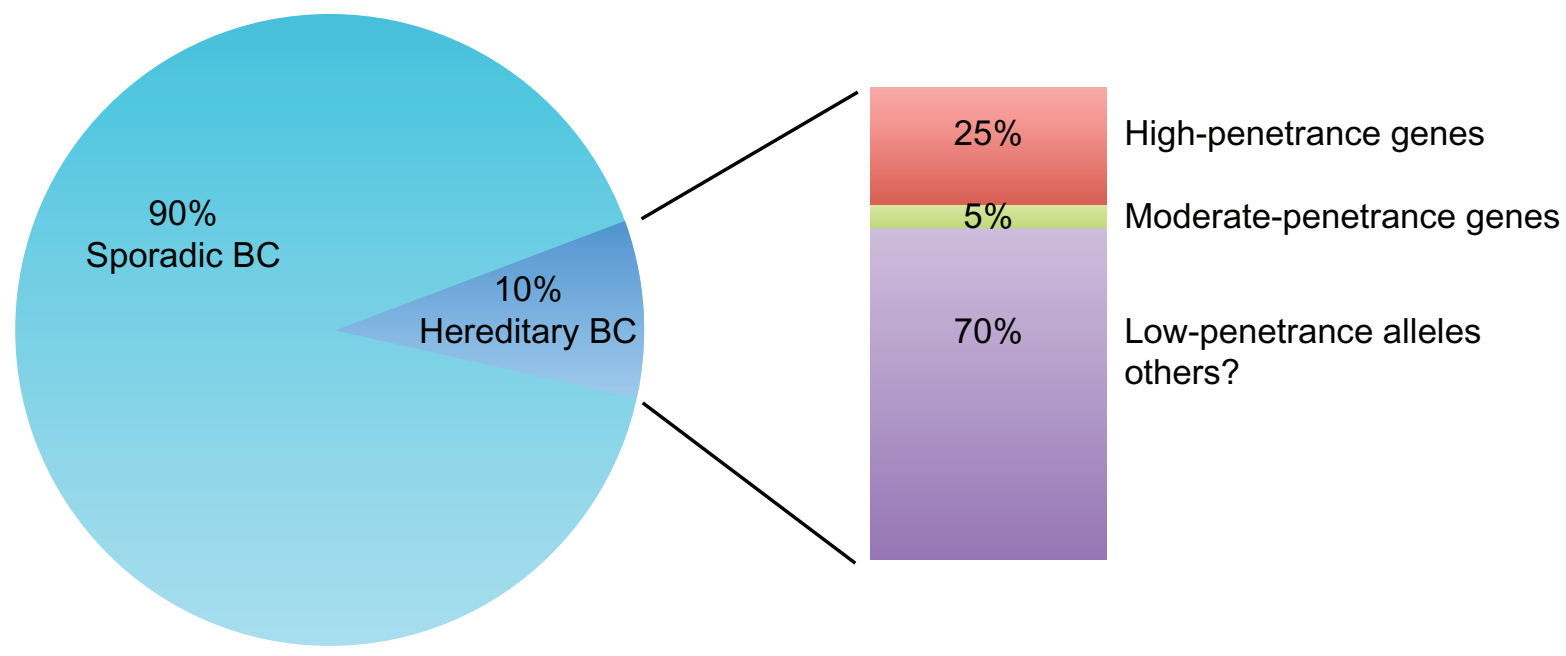

Figure I Genetic susceptibility in hereditary breast cancer. Up to $10 \%$ of all breast cancers are caused by inherited germ-line mutations in breast cancer susceptibility genes. High-penetrance genes (BRCAI and BRCA2) contribute to $25 \%$ of hereditary breast cancer, moderate-penetrance genes (CHEK2, ATM, PALB2, BRIPI, RAD5 IC) contribute less than $5 \%$ to the risk of breast cancer. The great majority of hereditary breast cancer may be due to common low-penetrance alleles or other still unknown genetic factors. Abbreviation: BC, breast cancer.

the protein product. The most common type of mutations are small frameshift insertions or deletions, nonsense mutations, or mutations affecting splice sites resulting in a deletion of complete or partial exons or insertion of intronic sequences. The Breast Cancer Linkage Consortium has reported that approximately $70 \%$ of $B R C A 1$ mutations and $90 \%$ of $B R C A 2$ mutations in linked families are truncating mutations. ${ }^{4}$ In addition to truncating mutations, an elevated number of missense variants has been identified. The most frequent are the $B R C A 1 \mathrm{G} 61 \mathrm{C}$ in the RING-finger codon and the BRCA2 I2490T in exon 15.

Some studies also indicate that BRCA1/2 polymorphic variants could be associated with an increased risk of breast and ovarian cancer. ${ }^{23,24}$ Association between the $B R C A 2 \mathrm{~N} 372 \mathrm{H}$ variant and increased breast cancer risk in particular has been reported from population-based studies. ${ }^{25}$ Interestingly, we observed an association between the $B R C A 2 \mathrm{~N} 372 \mathrm{H}$ variant and risk of male breast cancer in young patients. ${ }^{26}$ Breast cancer risk in women is influenced by the position of the mutation within the gene sequence. Women with a mutation in the central region of $B R C A l$ were shown to have a lower breast cancer risk than women with mutations outside this region. $B R C A 2$ mutations located in the central region, referred to as the ovarian cancer cluster region, also appear to be associated with a lower breast cancer risk and a higher ovarian cancer risk than other $B R C A 2$ mutations. ${ }^{27,28}$

Specific BRCA1 and BRCA2 mutations show a high frequency in specific countries or ethnic groups, particularly in genetically isolated populations. These mutations descend from a single founder. For example, two founder mutations in BRCA1 (185delAG and 5382insC) and one in BRCA2 (6174delT) account for the majority of all $B R C A 1 / 2$ mutations $(>90 \%)$ in the Ashkenazi Jewish population. ${ }^{29}$ BRCA1 185 delAG is present in about $1 \%$ of Ashkenazi Jews and in $20 \%$ of Ashkenazi women affected by breast cancer before

Table I Classes of genetic susceptibility and comparison of their different features

\begin{tabular}{|c|c|c|c|}
\hline & High-penetrance & Moderate-penetrance & Low-penetrance \\
\hline Genes & $B R C A I, B R C A 2$ & $\begin{array}{l}\text { CHEK2, ATM, PALB2, BRIPI, } \\
\text { RAD5IC }\end{array}$ & $\begin{array}{l}\text { I0q26.I3 (FGFR2), 2q33 (CASP8), 5qI I.2 } \\
\text { (MAP3KI), I IpI5.5 (LSPI), I6qI2.I (TNRC9), } \\
\text { 6q25 (ESRI), I4q24 (RAD5ILI), 2q35, } \\
\text { 8q24, 5pI2, IpII }\end{array}$ \\
\hline Population frequency & $<0.1 \%$ & MAF $<2 \%$ & MAF $>10 \%$ \\
\hline Cancer risk (odds ratio) & $>10.0$ & $>2.0$ & $1.1-1.6$ \\
\hline Population attributable risk & Small & Individually small & High \\
\hline Functional effect & Direct effect of mutation & Direct effect of variant & Linkage disequilibrium with causal variants \\
\hline Strategy for identification & $\begin{array}{l}\text { Linkage and positional cloning; } \\
\text { resequencing of candidate genes }\end{array}$ & $\begin{array}{l}\text { Resequencing of candidate } \\
\text { genes }\end{array}$ & $\begin{array}{l}\text { Case-control studies; genome-wide } \\
\text { association study }\end{array}$ \\
\hline
\end{tabular}


the age of 50 years. ${ }^{18,30} \mathrm{~A}$ single $B R C A 2$ mutation (999del5) has been found in the majority of multiple-case breast cancer families in the Icelandic population. ${ }^{31,32}$ The BRCA2 $999 \mathrm{del} 5$ accounts for about $8 \%$ of female breast cancer, rising to $24 \%$ of female breast cancers before the age of 40 years, and for about $38 \%$ of male breast cancers. ${ }^{32,33}$ In Italy, a historically and genetically heterogeneous country, BRCA1/2 founder mutations are found in small isolated geographic areas. The BRCA1 5083del19 was found in a geographically homogeneous population from Calabria, a region of Southern Italy, where it accounts for $33 \%$ of overall gene mutations. ${ }^{34} \mathrm{~A}$ high frequency of BRCA1 5083del19 mutation has also been identified in the population of Sicily, a region near to Calabria. ${ }^{35}$ Other regional founder mutations have been reported in Tuscany (BRCA1 1499insA, BRCA1 3347delAG), a region in Central Italy of ancient settlement. .1,22,36 $^{2}$

In addition to point mutations, small deletions and insertions, large-scale $B R C A 1 / 2$ rearrangements, including insertions, deletions, or duplications of more than $500 \mathrm{~kb}$ of DNA, have been identified in both male and female breast cancer. ${ }^{37-40}$ Large genomic rearrangements may account for $3 \%-15 \%$ of all BRCA1 and BRCA2 mutations. ${ }^{38}$ The higher density of $A l u$ repeat sequences in BRCA1 and both $A l u$ and non- $A l u$ repetitive DNA in $B R C A 2$ are thought to contribute to the large number of deletions and duplications observed in these genes. ${ }^{37,40-43}$ The frequency of large BRCA1 genomic rearrangements in families with a strong family history of breast and/or ovarian cancer, varies greatly $(0 \%-36 \%)$ in different populations. ${ }^{37-39}$ The frequency of large BRCA2 genomic rearrangements seems to be lower $(1 \%-2 \%)$ in comparison with $B R C A 1 .{ }^{41,44}$ Interestingly, large genomic rearrangements in $B R C A 2$ are more frequent in families with male breast cancer. ${ }^{38,43}$

\section{Moderate-penetrance breast cancer genes}

Overall, fewer than $10 \%$ of breast cancers are attributable to known mutations in the breast cancer susceptibility genes, BRCA1 and BRCA2. ${ }^{13}$ Recently, direct interrogation of candidate genes involved in $B R C A 1 / 2$-associated DNA damage repair pathway has led to the identification of other breast cancer susceptibility genes, classified as moderate-penetrance genes (Table 1). Variants found in this class of genes confer a smaller risk of breast cancer than $B R C A 1 / 2$ and, because of their rarity, are very difficult to detect in the population. Overall, mutations in moderatepenetrance genes account for less than $3 \%$ of the familial risk of breast cancer. ${ }^{13}$
CHEK2 1100delC was the first moderate breast cancer risk allele identified and was associated with a twofold risk among breast cancer cases unselected for family history and fivefold among familial breast cancer cases. ${ }^{45,46}$ The CHEK2 1100delC mutation has also been shown to confer approximately a tenfold increase in breast cancer risk in men lacking $B R C A 1 / 2$ mutations, and was estimated to account for $9 \%$ of familial high-risk male breast cancer cases. ${ }^{45}$ However, this association is not so evident in male breast cancer series unselected for family history, in which it was reported that the CHEK2 $1100 \mathrm{delC}$ is unlikely to account for a significant proportion of male breast cancer cases. ${ }^{47-50}$ The contribution of the CHEK2 $1100 \mathrm{delC}$ mutation to breast cancer predisposition in both genders varies by ethnic group and from country to country. A decreased frequency of the $1100 \mathrm{delC}$ allele in North to South orientation has been observed in Europe both for male and female breast cancer. ${ }^{50-53}$ Identification of the CHEK2 1100delC mutation as a breast cancer-associated allele induced mutational screening of the whole CHEK2 gene sequence. However, at present, only a small number of rare truncating mutations and missense variants have been reported in breast cancer cases. ${ }^{54,55}$

ATM was first proposed as a breast cancer predisposition gene by epidemiological studies that reported an increased breast cancer risk in relatives of patients with ataxia telangiectasia, a recessive syndrome caused by mutation in the ATM gene ${ }^{56,57}$ However, molecular data corroborating this observation were provided after 20 years. ${ }^{58}$ To date, many truncating splice site mutations and missense variants for $A T M$ have been found and associated with a relative risk of breast cancer of about $2.4{ }^{58}$ Currently there are no data about the role of ATM in men predisposed to breast cancer.

The involvement of BRCA2 in the Fanconi anemia pathway promoted mutation screening of other Fanconi anemia genes functionally linked to $B R C A 2$, such as $P A L B 2$, $B R I P 1$, and, more recently, RAD51C. ${ }^{59} P A L B 2$ truncating mutations were estimated to be associated with a 2.3 -fold increased risk. ${ }^{60}$ PALB2 mutations have now been identified in many countries, with frequencies varying from $0.6 \%$ to $2.7 \%$ in familial breast cancer cases. ${ }^{61-69}$ Two founder PALB2 mutations, 1592 delT and $2323 \mathrm{C}>\mathrm{T}$, were respectively identified in $1 \%$ of Finnish and $0.5 \%$ of French-Canadian breast cancers unselected for family history. ${ }^{70,71}$ Interestingly, PALB2 mutations were found in families with both female and male breast cancer cases, suggesting that $P A L B 2$ may be involved in male breast cancer risk. ${ }^{60,67}$ To date, five studies 
have reported on the frequency of $P A L B 2$ mutations in male breast cancer..$^{70,72-75}$ Overall, PALB2 seems to have a role as a moderate-penetrance gene in male breast cancer to a comparable extent as for female breast cancer. Recently, it has been reported that $P A L B 2$ heterozygote mutation carriers were four times more likely to have a male relative with breast cancer. $^{76}$

Deleterious BRIP1 mutations were initially estimated to confer a twofold increased breast cancer risk and to account for about $1 \%$ of $B R C A 1 / 2$ negative familial/early-onset breast cancer cases, but further studies suggested that the BRIPI contribution to breast cancer susceptibility might be more limited than initially reported. ${ }^{77-80}$ Indeed, a total of only eight BRIP1 truncating mutations in 11 BRCA1/2 mutationnegative breast cancer cases from three independent studies have been identified worldwide. ${ }^{77,81,82}$ Several studies in diverse populations failed to detect truncating mutations. ${ }^{78-80}$ To date, only one study has investigated the role of BRIPI in male breast cancer susceptibility, and no evidence was found that germ-line variants in BRIPI might contribute to male breast cancer predisposition. ${ }^{83}$ Taken together, these data suggest that the contribution of BRIP 1 to breast cancer predisposition in both females and males is less consistent compared with other moderate breast cancer susceptibility genes, such as CHEK2 and PALB2.

Recently, mutations in $R A D 51 C$, another gene associated with Fanconi anemia, were identified as breast cancer susceptibility alleles, accounting for $1.3 \%$ of female patients from families with at least one case each of breast and ovarian cancer. ${ }^{84}$ However, further studies did not confirm this frequency. ${ }^{85,86}$ At present, there is no evidence that $R A D 51 C$ mutations contribute to male breast cancer susceptibility. ${ }^{87}$

\section{Low-penetrance breast cancer genes}

A polygenic model, in which many genes that confer low risk individually act in combination to confer much larger risk in the population, has been suggested for susceptibility to breast cancer and other common cancers. ${ }^{88}$ Breast cancers unaccounted for by currently known high-penetrance and moderate-penetrance breast cancer susceptibility genes can be explained by this model. This hypothesis, speculated for years, has only recently been confirmed by multigroup collaborations working in genome-wide association studies performed in a very large series of cases and controls from different countries, in order to increase the power to detect small effects on risk. ${ }^{89,90}$ Common low-penetrance breast cancer susceptibility single nucleotide polymorphisms have thus far been reported in regions that cover known proteincoding genes, including CASP8, FGFR2, TNRC9, MAP3K1, $L S P 1, R A D 51 L 1$, and ESR1 and in regions such as 8q24, $2 \mathrm{q} 35,5 \mathrm{p} 12$, and $1 \mathrm{p} 11$ with no known protein-coding genes (Table 1). ${ }^{90-95}$ The relative risk conferred by these alleles ranges from 1.07 to 1.26 . Overall, these single nucleotide polymorphisms are estimated to account for less than $4 \%$ of the familial risk of breast cancer in women. ${ }^{90}$ Interestingly, many of the alleles are in intronic portions of genes, and often are noncoding regions that may confer susceptibility. This might be explained by the observation that some of these loci are located in regions of linkage disequilibrium that cover different genes, but it is very difficult to establish which of a set of variants in linkage disequilibrium is the most functionally relevant. ${ }^{96}$ Furthermore, some of these single nucleotide polymorphisms, including CASP8, FGFR2, TOX3, and MAP3K1, could act as modulators of the risk conferred by mutations in the high-penetrance breast cancer susceptibility genes, $B R C A 1$ and $B R C A 2 .{ }^{97}$ Recently, a subtle regulatory effect of one allele in the prostate/breast cancer-associated 8q24 block was also demonstrated, which acts as a cis enhancer of the $M Y C$ promoter. ${ }^{98}$ Interestingly, different haplotype blocks within 8q24 were specifically associated with risk of different cancers. ${ }^{99}$ In particular, four blocks were site-specific (one for breast cancer and three for prostate cancer), and a fifth was a multicancer susceptibility marker because it was associated with a risk of various cancers, including prostate, colon, ovarian, kidney, thyroid, and laryngeal cancer, but not breast cancer. ${ }^{99-101}$ None of the presently identified loci is directly linked to the DNA repair pathway. Instead, many of the coding loci are in genes somatically mutated in diverse cancers, including breast cancer. Recently, it was observed that genetic germ-line variations in genes encoding for "driver kinases" may influence breast cancer risk, thus suggesting that low-penetrance alleles might be a link between germ-line and somatic alterations in breast cancer. ${ }^{102}$

Specific single nucleotide polymorphisms seem to be associated with specific clinicopathological features. In particular, loci at $F G F R 2, M A P 3 K 1$, and 2q35 were found to associate specifically with estrogen receptor-positive breast cancer. ${ }^{92,103,104}$ Data are still limited for less common tumor subtypes, such as estrogen receptor-negative or basal-like breast tumors. Whether these loci are associated with the risk of breast cancer in males has not yet been investigated, but an involvement of low-penetrance alleles in male breast cancer susceptibility cannot be excluded and warrants ad hoc studies. 


\section{Acquired alterations in breast cancer}

Breast cancer development and progression is a multistep process resulting from the accumulation of genetic alterations, such as mutations and copy number variations, and also epigenetic alterations, such as promoter methylation, resulting in aberrant gene expression. The increasing number of deregulated genes subsequently affects important cellular networks, such as cell cycle control, DNA repair, cell adhesion or migration, and differentiation, driving normal breast cells into highly malignant derivatives with metastatic potential. Such alterations can result either in inactivation of tumor suppressor genes (eg, TP53, BRCA1) or activation of protoncogenes (eg, PIK3CA, MYC), both of which contribute to the malignant state of a transformed cell. Recent landmark studies have shed new light on the genomic landscape of breast cancer. Within a breast tumor there are many infrequently mutated genes and a few frequently mutated genes, resulting in incredible genetic heterogeneity. ${ }^{105,106}$ The great majority of somatic mutations frequently lie in hotspot regions that might represent targets in cancer therapy. Both genetic and epigenetic alterations are also frequently associated to specific biological and clinicopathological tumor characteristics, allowing the identification of personalized therapies targeting the associated molecular pathways. ${ }^{107-116}$

\section{Genetic alterations in breast cancer}

A number of gene and chromosome alterations have been identified in sporadic breast carcinomas. Indeed, the great majority of breast cancer cases are due to solely somatic genetic alterations without germ-line ones. ${ }^{117,118} \mathrm{~A}$ heterogeneous set of somatic alterations, including gene amplification, deletion, mutations, and rearrangements, were reported to be involved in the etiology of breast cancer. ${ }^{6}$ The amount of information on these alterations has been dramatically increased by the introduction of high-throughput molecular cytogenetic approaches. Using large-scale approaches, the sequence of about 18,000 genes has been analyzed in breast cancer cases, and it has been reported that about $10 \%$ of these had at least one nonsilent mutation. ${ }^{105}$ The great majority of alterations are single base substitutions (about 90\%), with a prevalence of missense changes $(60 \%$, Figure 2$)$. The remainder are somatic mutations resulting in stop codon or splice site alterations, and only a few of these are insertions, deletions, or duplications ${ }^{105}$ (Figure 2). Somatic mutations found in cancers can be subdivided mainly into two biological classes, ie, "driver" and "passenger" mutations. Driver mutations confer proliferative advantage to tumor cells and

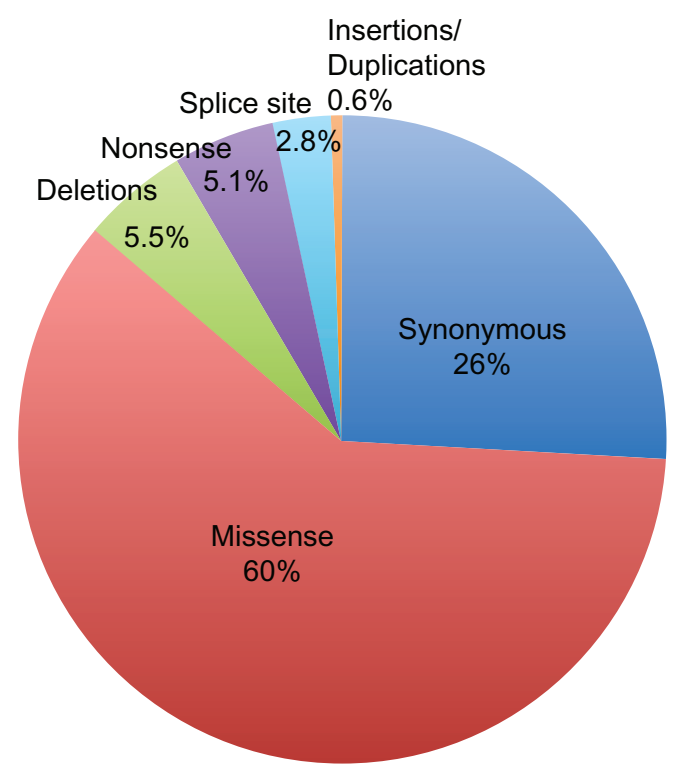

Figure 2 Somatic mutations in breast cancer.The great majority of somatic mutations are single base substitutions, mainly missense mutations; missense changes account for about $60 \%$ of somatic alterations; the remaining somatic mutations result in stop codon $(5.1 \%)$ or in alterations of splice site $(2.8 \%)$ and only a few percentages of these are insertions, deletions, or duplications (5.6\%).

are positively selected during cancer development. Passenger mutations are present in the tumor progenitor cells, are biologically neutral, and do not confer a growth advantage. ${ }^{105}$

Several studies have shown a bimodal distribution of mutations in breast cancer. It has been proposed that the genomic landscape of breast cancer consists of "mountains" and "hills," where the mountains correspond to the most frequently mutated genes, specifically PIK3CA and TP53, and the hills consist of a much larger number of less frequently mutated cancer-associated genes $(<5 \%)$. ${ }^{105,106}$ Additional to mutations in PIK3CA and P53, alterations in several genes implicated in pathways involved in breast tumorigenesis, including the phosphatidylinositol 3-kinase/Akt and NF-kB pathways, have been also identified (eg, IKBKB, IRS4, NFKBIA, NFKBIE, NFKB1, PIK3R1, PIK3R4, RPS6KA3, MAP3K1, AKT1, and GATA3 genes). ${ }^{105,119,120}$ These genes could be considered the hills of the mutational landscape of breast cancer, because their mutation frequencies are lower than for genes considered to be the mountains.

Mutations of the PIK3CA gene are observed in 16\%-40\% of female breast cancers and in about $18 \%$ of male breast cancers. ${ }^{109,121-124}$ PIK3CA mutations are associated with a positive estrogen receptor and progesterone receptor status, nodal involvement, and high histological grade, suggesting that they could be strong prognostic factors in breast cancer. ${ }^{107-110}$ The great majority (85\%) of PIK3CA mutations are in exons 9 and 20, encoding the helical and kinase 
domains, respectively. The majority of mutations are located in two hot spot regions, including the central helical domain and the $\mathrm{COOH}$ terminal kinase domain. The three most common hot spot mutations lead to amino acid changes in the helical domain (E542K and E545K) and in the kinase domain (H1047R). ${ }^{125}$ In particular E542K, E545K, and H1047R represent $3.6 \%, 6.2 \%$, and $14.8 \%$ of the total PIK3CA mutations in breast cancer, respectively. ${ }^{125}$

Mutations of the TP53 gene in breast cancer range from $15 \%$ to $71 \%$ among different populations. ${ }^{126}$ More than $90 \%$ of TP53 mutations reported in breast cancer are located in conservative regions within exons 5 to $8 .{ }^{126,127}$ More than $2 \%$ of all TP53 mutations are represented by three TP53 hot spot mutations, ie, 273 (CGT > CAT), 158 (CGC > CTC), and 248 (CGG > CAG) ${ }^{128}$ However, an overrepresentation of codon 163 (TAC > TGC) mutation has been observed in breast cancer. Indeed, this codon, rarely mutated in most cancers, accounts for over $2 \%$ of all breast cancer mutations. Interestingly, codon 163 is a hot spot for TP53 mutation in breast cancer among BRCA1/2 carriers. ${ }^{127}$ Overall, TP53 mutations are strongly associated with high histological grade, negative estrogen receptor status, increased global genomic instability, and germ-line BRCA1 mutations. ${ }^{111-113}$ At least 14 different common polymorphisms have been described in the TP53 gene (IARC p53 data base www.p53. iarc.fr/p53main.html). The most common TP53 polymorphic variants are the $16 \mathrm{bp}$ duplication in intron 3 (TP53PIN3) and the TP53 G215C (Arg72Pro). There is some evidence of an association between TP53PIN3 and Arg72Pro variants and elevated breast cancer risk, although some studies suggest a neutral or protective effect for these polymorphisms. ${ }^{129-131}$ Genotype and haplotype analyses of these two TP53 polymorphisms also revealed that the presence of a specific haplotype carrying the consensus sequence for TP53PIN3 (allele without the $16 \mathrm{bp}$ insertion), and the variant allele for Arg72Pro (72Pro) is associated with an earlier age at onset of breast cancer in BRCA2 mutation carriers. ${ }^{132,133}$

In addition to nonsynonymous mutations arising from single nucleotide substitutions, several splice variants specific to breast cancer have been reported. ${ }^{134,135}$ Interestingly, breast cancer-specific alternative splicing is not restricted to splicing defects resulting in loss of protein functions, and may also include modifications that generate proteins with new functions. ${ }^{134}$

Alternative splicing events can involve breast cancerspecific genes, such as BRCA1, ESR2, and HER2, or genes involved in cell cycle progression, DNA damage response, and spliceosome assembly. ${ }^{134,136-138}$ The number of known
BRCA1 mRNA variants representing aberrant splicing products is relatively high. ${ }^{136}$ The four predominant mRNA variants with a molecular weight lower than full length BRCA1 are $\Delta(9,10), \Delta(9,10,11 \mathrm{q}), \Delta(11 \mathrm{q})$, and $\Delta(11)$. The variants that would be expected to differ the greatest at the functional level from the full length species are those lacking the largest exon 11, containing many functional domains involved in protein-protein interaction. ${ }^{136}$

Different ESR2 (estrogen receptor $\beta$ ) splice variants have been identified, and studies on the function of some of these suggested that they might act as a dominant negative receptor in the estrogen receptor $\alpha$ and $\beta$ pathways. ${ }^{135,139}$

A specific splicing variant of HER2 ( $\triangle \mathrm{HER} 2)$, which causes lack of exon 16 encoding the extracellular domain, has been identified in $9 \%$ of breast cancers overexpressing HER2 protein, suggesting that HER2 proteins carrying splicing variants may represent the oncogenic receptor population. ${ }^{137,140}$

Different alternative splicing events have been identified, in which changes in splicing correlate with estrogen receptor status and histological tumor grade. ${ }^{134}$ Thus, analysis of alternative splicing might provide information about the biology of the tumor.

Genomic instability, such as gene copy number alterations and DNA amplifications, has also been observed frequently in breast cancer. The most commonly amplified regions in breast cancer include 8q24, 11q13, 12q14, 17q11, $17 q 24$, and 20q13, with amplification of genes such as HER2 (15\%-20\%), EGFR (14\%), MYC (15\%-20\%), CCND1 (15\%-20\%), ESR1 (20\%), and EMSY (7\%-13\%). ${ }^{14,141,142}$ Amplification of these regions increases genetic instability in breast cancer and is generally associated with poor prognosis. ${ }^{114}$

HER 2 and EGFR are members of the epidermal growth factor receptor family, and both genes are targets for copy number amplification in breast cancer. ${ }^{143}$ Amplification of the HER 2 gene causes HER2 protein levels that are 10-100 times greater than normal. HER2-positive breast cancers are associated with a worse prognosis and resistance to hormonal therapy. ${ }^{144,145}$ EGFR upregulation in breast cancer is not only due to gene amplification but often results from either high polysomy of chromosome 7 or transcriptional induction by the transcription factor YBX1 (Y box binding protein 1). ${ }^{146}$ EGFR amplification is frequently associated with poor prognosis parameters in breast cancer patients, such as large tumor size, high histological grade, high proliferative index, and negative estrogen receptor status. ${ }^{147,148}$ Moreover, increased EGFR gene copy numbers are observed 
in triple-negative (estrogen receptor, progesterone receptor, and HER2 negative) breast cancers together with decreased BRCA1 mRNA expression. ${ }^{149}$

MYC functions as a transcription factor, regulating up to $15 \%$ of all human genes. Although the relationship between amplification and overexpression is not clearly delineated, $M Y C$ amplification is significantly correlated with aggressive tumor phenotypes and poor clinical outcomes. MYC amplification is emerging as an important predictor of response to HER2-targeted therapies, and its role in BRCA1-associated breast cancers makes it an important target in basal-like/ triple-negative breast cancers. ${ }^{150}$

Other two genes frequently amplified in breast cancer are ESR1 and CCND1. Amplification of ESR1 is associated with the expression of the estrogen receptor in breast cancer. ${ }^{151}$ Overall, higher ESR 1 gene amplification is found in tumors with $C C N D 1$ gene amplification in comparison with tumors without $C C N D 1$ gene amplification. ${ }^{151} C C N D 1$ amplification occurred preferentially in estrogen receptorpositive breast cancer and is associated with reduced overall survival. ${ }^{152-155}$ Tumors which are sufficiently genetically unstable to develop one gene amplification have increased probability of developing multiple gene amplifications. The coamplification of one or several oncogenes, such as $E G F R$, ErbB2, CCND1, or ESR1, occurs commonly in breast cancer, and is reported in up to $30 \%$ of $C C N D 1$-amplified and up to $40 \%$ of ErbB2-amplified tumors. ${ }^{114}$

EMSY amplification in sporadic breast tumors has been shown to be associated with a poor prognosis. ${ }^{141}$ Amplification of EMSY has been reported in sporadic breast cancer but not in $B R C A 2$-associated breast cancer, suggesting that $B R C A 2$ mutations and EMSY gene amplification may be mutually exclusive. ${ }^{156}$ Indeed, EMSY protein interacts with the transactivation domain of BRCA2, reducing its activity, and it has been suggested that amplification of EMSY can explain somatic $B R C A 2$ inactivation. ${ }^{156}$

Recently it has been reported that male breast cancers have a lower frequency of gene copy number alterations than female breast cancers. ${ }^{157}$ Moreover, different chromosomal regions were found to be altered in male and female breast cancer. Male breast cancer alterations targeted $\mathrm{Xp} 11.23$ and $14 \mathrm{q} 13.1$ regions in more than $50 \%$ of cases. Shared amplified regions between male and female breast cancers are 8q24 (53\%), 11q13 (50\%), and 17q24 (30\%), mapping for $M Y C, E M S Y$, and HER2, respectively. ${ }^{117,157}$ Furthermore, HER2 and CCND1 gene amplification is observed in about $8 \%$ and $12 \%$ of male breast cancer cases, respectively. ${ }^{158,159}$

\section{Epigenetic alterations}

Epigenetic changes, in particular DNA methylation, are emerging as one of the most important events involved in breast cancer initiation and progression, and there is evidence that DNA methylation may serve as a link between genome and environment. Interestingly, factors that can be modulated by the environment, such as estrogens, elicit epigenetic changes (such as DNA methylation) and this could contribute to breast cancer risk. Furthermore, tumor-specific $\mathrm{CpG}$ island hypermethylation profiles are now emerging in breast cancer. ${ }^{7}$ Tumor-related genes that become hypermethylated may play a significant role in breast cancer, including $B R C A 1$ and hormone response genes, such as estrogen, progesterone, androgen, and prolactin receptors. ${ }^{160}$ Epigenetic silencing is one of the mechanisms by which mammary epithelial cells repress estrogen receptor expression, leading to the estrogen receptor-negative molecular subtypes of breast cancer. ${ }^{161}$ ESR 1 methylation is more common in estrogen receptor-negative than in estrogen receptor-positive tumors, but there is no clear link between ESR 1 methylation and estrogen receptor status. It has been suggested that a heterogeneous ESRl gene methylation pattern may evolve during breast cancer progression and play a role in estrogen receptor-negative recurrences or metastases in patients with estrogen receptor-positive tumors. ${ }^{162}$ Interestingly, breast tumors with $B R C A 1$ methylation show a high frequency of ESR 1 promoter methylation. BRCA1 somatic mutations are extremely rare in sporadic breast cancer, but $9 \%-13 \%$ of these tumors reveal aberrant $B R C A 1$ methylation, especially when loss of heterozygosity occurs at the BRCA1 locus. ${ }^{160}$ $B R C A 1$-associated breast cancers are generally basal-like tumors, and promoter methylation is one mechanism of $B R C A 1$ gene silencing in sporadic basal-like breast cancers. However, there is no significant difference in BRCA1 methylation between sporadic basal-like breast cancers (14\%) and matched sporadic nonbasal-like breast cancers (11\%). BRCA1 methylation also appears to be similar across distinct breast cancer molecular subtypes $(14 \%-17 \%)$ including ductal, mucinous, and lobular breast cancers. ${ }^{163,164}$

Tumor-specific $\mathrm{CpG}$ island hypermethylation profiles are emerging, and the growing list of genes inactivated by promoter hypermethylation in breast cancer include genes involved in evasion of apoptosis (RASSF 1A, HOXA5, TWIST1), in cell cycle control (CCND2, p16, RAR $\beta$ ), and tissue invasion and metastasis $(C D H 1)$. Tumor suppressor genes, such as GSTP1, RIL, HIN-1, CDH13, APC, and $R U N X 3$, are frequently methylated in breast cancer tissues. ${ }^{15,161,165}$ These genes are not only hypermethylated 
in tumor cells, but show increased epigenetic silencing in normal epithelium surrounding the tumor site. Thus, methylation frequently represents an early event in breast cancer tumorigenesis. For example, $C C N D 2$, an important regulator of the cell cycle, has been frequently found to be methylated in breast cancer and is also methylated in ductal carcinoma in situ, suggesting that it may represent an early event in tumorigenesis. ${ }^{161}$ Another gene frequently hypermethylated in breast cancer is RASSF $1 A$. RASSF $1 A$ methylation is also an early epigenetic event in breast cancer and is found in ductal carcinoma in situ and in lobular carcinoma in situ. ${ }^{160}$ Its diverse functions include regulation of apoptosis, growth regulation, and microtubule dynamics during mitotic progression. ${ }^{161}$

There is some evidence that DNA hypermethylation patterns can identify breast cancer subgroups having distinctive biological properties that could be used for prognostication and for prediction of response to therapy. ${ }^{115,166,167}$ An association between methylation in five genes, including $R A R b, C D H 1, C C N D 2, p 16$, and ESR1, and poor histological differentiation of breast cancer is frequently reported. ${ }^{115,161}$ Furthermore, distinct epigenetic profiles can be identified when dividing breast tumors into groups based on hormone receptor status. ${ }^{166,168}$ Differences in methylation status of the promoter region $\mathrm{CpG}$ islands of major breast cancer tumor-related genes, such as RASSF1, CCND2, GSTP1, TWIST, RARb, and $C D H 1$, have been found relating to estrogen receptor and HER2 status. ${ }^{115}$ In particular, methylation of these tumor-related genes resulted in significantly higher estrogen receptor-positive and HER2-positive breast tumors. ${ }^{115,161}$ On the other hand, double-negative (estrogen receptor-negative, HER2-negative) breast cancers have significantly lower frequencies of RASSF1, GSTP, and APC methylation. Interestingly, epigenetic differences between estrogen receptor-positive and estrogen receptor-negative breast cancer arise early in cancer development and persist during cancer progression. ${ }^{115}$

\section{Micro RNA}

miRNAs are small noncoding, double-stranded RNA molecules involved in post-transcriptional regulation of target genes. Aberrant expressions of miRNA are associated with cancer progression, by acting either as tumor suppressor genes or oncogenes. ${ }^{8,169}$ Much attention has been paid to deregulation of gene expression through the action of specific miRNA in breast cancer. Microarray studies demonstrated that overall miRNA expression could clearly separate normal versus cancerous breast tissue, with the most significantly deregulated miRNAs being mir-125b, mir-145, mir-21, mir-155, and mir-335. ${ }^{170-172}$ Interestingly, a large number of miRNAs, overexpressed or underexpressed in breast cancer, are predicted to regulate expression of key breast cancer proteins, such as BRCA1/2, ATM, PTEN, CHEK2, MLH1, P53, and ER. ${ }^{169}$ Moreover, specific miRNAs, including miRNAs that regulate genes involved in cell proliferation, such as MAPK, RAS, HER2, HER3, and ESR1, have been shown to play a direct role in male breast cancer development. ${ }^{173,174}$ Indeed, cluster analysis of miRNA expression profiles reveals cancer-specific alterations of miRNA expression in male breast cancer distinct from female breast cancer, such as downregulation of miRNAs that suppress HOXD10, a protein involved in cell proliferation and migration, and vascular endothelial growth factor. ${ }^{173}$

Significant differences in miRNA expression profiles associated with molecular subtypes of breast cancer and correlated with specific clinicopathological factors, such as estrogen receptor, progesterone receptor, and HER2 status, emerged in breast cancer. ${ }^{170}$ Thus, evaluation of the associations between miRNA expression profiles and clinicopathological characteristics may be important to identify distinct breast cancer subgroups and may lead to improvements in the clinical management of breast cancer patients. Indeed, some miRNAs, including mir-21 and mir-145, have been shown to have potential clinical applications as novel biomarkers in the diagnosis and prognosis of breast cancer. ${ }^{175,176}$ Moreover, miRNAs may act as strong inhibitors of cellular pathways via regulation of entire sets of genes, thus suggesting a possibly great potential for miRNAs in breast cancer prevention and therapeutics. $^{116}$

\section{Future research directions}

Recent advances in technology have shed more light on the complexity of breast cancer biology and have provided data that allow risk estimation for patients with inherited mutations, prognostic and predictive determinations for patients with sporadic breast cancer, and targets for therapies. Recently, loci identified by genome-wide association studies have greatly expanded the list of genes associated with breast cancer risk.

However, evaluation of the functional consequences of low-penetrance alleles in breast cancer risk and their association with breast cancer molecular subtypes and clinicopathological characteristics are still challenging, but are needed for clinical application. Moreover, exploration of the polygenic model proposed for low-penetrance alleles requires further research in diverse and large populations. Overall, despite the 
remarkable efforts made in recent years, much of the complex landscape of familial breast cancer risk remains unknown, suggesting the need for ongoing efforts in this field. ${ }^{96}$

The introduction of high-throughput molecular approaches has greatly increased the amount of information on the genomic landscape of breast tumors. Serial analysis of the cancer genome in different phases of its evolution might lead to improved management of the individual breast cancer patient. ${ }^{118}$

Moreover, studying the global methylation status as well as miRNA expression profiles of different types of tumors will allow the development of profiles unique for breast cancer and its subtypes, staging, and prognostic categories, leading to diagnostic applications and identification of new therapeutic targets. ${ }^{116,171}$

\section{Conclusion}

The identification of breast cancer susceptibility genes, in particular $B R C A 1$ and $B R C A 2$, has changed the management of breast cancer patients with a family history of breast cancer. Several models have been developed, and are currently used to assess the pretest probability of identifying $B R C A 1 / 2$ germ-line mutations in individuals at risk for hereditary breast and ovarian cancer. Moreover, novel therapeutic strategies specific for $B R C A 1$ and $B R C A 2$ cancers are emerging, including crosslinking agents and poly ADP ribose polymerase inhibitors. ${ }^{156}$

Both genetic and epigenetic acquired alterations are frequently associated with specific biological and clinicopathological tumor characteristics, allowing identification of personalized therapies targeting specific molecular pathways. In particular, a number of compounds, including trastuzumab, lapatinib, and pertuzumab, are currently under clinical evaluation for HER2-targeted therapy. ${ }^{177}$ However, the majority of HER2-overexpressing breast cancers do not respond to HER2-targeted therapy alone. ${ }^{178}$ There is evidence showing that combination therapy involving the use of HER2 and endothelial growth factor receptor inhibitors, such as trastuzumab and lapatinib, may have promising results in breast cancer treatment. ${ }^{178}$ Crosstalk between the endothelial growth factor receptor/HER2 and phosphatidylinositol 3-kinase/Akt pathways provides a rationale for combining anti-endothelial growth factor receptor/HER2 agents and inhibitors of phosphatidylinositol 3-kinase/Akt/mTOR in breast cancer. In addition, DNA methylation as well as miRNAs are currently emerging as interesting candidates for the development of therapeutic strategies against breast cancer. In conclusion, elucidation of the inherited and acquired genetic and epigenetic alterations involved in breast cancer has not only clarified the molecular pathways involved in development and progression of breast cancer itself, but may also have important clinical and therapeutic implications in the management of patients with breast cancer.

\section{Disclosure}

The authors report no conflicts of interest in this work.

\section{References}

1. Willems PG. Susceptibility genes in breast cancer: more is less? Clin Genet. 2007;72:493-496.

2. Anderson WF, Jatoi I, Tse J, Rosenberg PS. Male breast cancer: a population-based comparison with female breast cancer. J Clin Oncol. 2010;28:232-239.

3. Martin AM, Weber BL. Genetic and hormonal risk factors in breast cancer. J Natl Cancer Inst. 2000;92:1126-1135.

4. Thompson D, Easton D. The genetic epidemiology of breast cancer genes. J Mammary Gland Biol Neoplasia. 2004;9:221-236.

5. Lee EY, Muller WJ. Oncogenes and tumor suppressor genes. Cold Spring Harb Perspect Biol. 2010;2:a003236.

6. Stephens PJ, McBride DJ, Lin ML, et al. Complex landscapes of somatic rearrangement in human breast cancer genomes. Nature. 2009;462:1005-1010.

7. Esteller M. Cancer epigenomics: DNA methylomes and histonemodification maps. Nat Rev Genet. 2007;8:286-298.

8. Croce CM. Causes and consequences of microRNA dysregulation in cancer. Nat Rev Genet. 2009;10:704-714.

9. Hirshfield KM, Rebbeck TR, Levine AJ. Germline mutations and polymorphisms in the origins of cancers in women. J Oncol. 2010. Epub 2010 Jan 10.

10. Borresen AL, Andersen TI, Garber J, et al. Screening for germ line TP53 mutations in breast cancer patients. Cancer Res. 1992;52: 3234-3236.

11. Chen J, Lindblom P, Lindblom A. A study of the PTEN/MMAC1 gene in 136 breast cancer families. Hum Genet. 1998;102:124-125.

12. Wooster R, Weber BL. Breast and ovarian cancer. $N$ Engl J Med. 2003;348:2339-2347.

13. Stratton MR, Rahman N. The emerging landscape of breast cancer susceptibility. Nat Genet. 2008;40:17-22.

14. Nathanson KL, Wooster R, Weber BL. Breast cancer genetics: what we know and what we need. Nat Med. 2001;7:552-556.

15. Martin AM, Blackwood MA, Antin-Ozerkis D, et al. Germline mutations in BRCA1 and BRCA2 in breast-ovarian families from a breast cancer risk evaluation clinic. J Clin Oncol. 2001;19: 2247-2253.

16. Liebens FP, Carly B, Pastijn A, Rozenberg S. Management of BRCA1/2 associated breast cancer: a systematic qualitative review of the state of knowledge in 2006. Eur J Cancer. 2007;43:238-257.

17. Ford D, Easton DF, Stratton M, et al. Genetic heterogeneity and penetrance analysis of the BRCA1 and BRCA2 genes in breast cancer families. The Breast Cancer Linkage Consortium. Am J Hum Genet. 1998;62:676-689.

18. Antoniou A, Pharoah PD, Narod S, et al. Average risks of breast and ovarian cancer associated with BRCA1 or BRCA2 mutations detected in case series unselected for family history: a combined analysis of 22 studies. Am J Hum Genet. 2003;72:1117-1130.

19. Chen S, Iversen ES, Friebel T, et al. Characterization of BRCA1 and BRCA2 mutations in a large United States sample. J Clin Oncol. 2006; 24:863-871.

20. Frank TS, Deffenbaugh AM, Reid JE, et al. Clinical characteristics of individuals with germline mutations in BRCA1 and BRCA2: analysis of 10,000 individuals. J Clin Oncol. 2002;20:1480-1490. 
21. Ottini L, Rizzolo P, Zanna I, et al. BRCA1/BRCA2 mutation status and clinical-pathologic features of 108 male breast cancer cases from Tuscany: a population-based study in central Italy. Breast Cancer Res Treat. 2009; 116:577-586.

22. Papi L, Putignano AL, Congregati C, et al. Founder mutations account for the majority of BRCA1-attributable hereditary breast/ovarian cancer cases in a population from Tuscany, Central Italy. Breast Cancer Res Treat. 2009; 117:497-504.

23. Durocher F, Shattuck-Eidens D, McClure M, et al. Comparison of BRCA1 polymorphisms, rare sequence variants and/or missense mutations in unaffected and breast/ovarian cancer populations. Hum Mol Genet. 1996;5:835-842.

24. Dunning AM, Chiano M, Smith NR, et al. Common BRCA1 variants and susceptibility to breast and ovarian cancer in the general population. Hum Mol Genet. 1997;6:285-289.

25. Qiu LX, Yao L, Xue K, et al. BRCA2 N372H polymorphism and breast cancer susceptibility: a meta-analysis involving 44,903 subjects. Breast Cancer Res Treat. 2010;123:487-490.

26. Palli D, Falchetti M, Masala G, et al. Association between the BRCA2 $\mathrm{N} 372 \mathrm{H}$ variant and male breast cancer risk: a population-based casecontrol study in Tuscany, Central Italy. BMC Cancer. 2007;7:170.

27. Thompson D, Easton D. Breast Cancer Linkage Consortium. Variation in cancer risks, by mutation position, in BRCA2 mutation carriers. Am J Hum Genet. 2001;68:410-419.

28. Thompson D, Easton D. Breast Cancer Linkage Consortium. Variation in BRCA1 cancer risks by mutation position. Cancer Epidemiol Biomarkers Prev. 2002;11:329-336.

29. Phelan CM, Kwan E, Jack E, et al. A low frequency of non-founder BRCA1 mutations in Ashkenazi Jewish breast-ovarian cancer families Hum Mutat. 2002;20:352-357.

30. Struewing JP, Abeliovich D, Peretz T, et al. The carrier frequency of the BRCA1 185delAG mutation is approximately 1 percent in Ashkenazi Jewish individuals. Nat Genet. 1995;11:198-200.

31. Gudmundsson J, Johannesdottir G, Arason A, et al. Frequent occurrence of BRCA2 linkage in Icelandic breast cancer families and segregation of a common BRCA2 haplotype. Am J Hum Genet. 1996;58: 749-756.

32. Thorlacius S, Olafsdottir G, Tryggvadottir L, et al. A single BRCA2 mutation in male and female breast cancer families from Iceland with varied cancer phenotypes. Nat Genet. 1996;13: $117-119$.

33. Johannesdottir G, Gudmundsson J, Bergthorsson JT, et al. High prevalence of the 999del5 mutation in Icelandic breast and ovarian cancer patients. Cancer Res. 1996;56:3663-3665.

34. Baudi F, Quaresima B, Grandinetti C, et al. Evidence of a founder mutation of BRCA1 in a highly homogeneous population from southern Italy with breast/ovarian cancer. Hum Mutat. 2001;18:163-164.

35. Russo A, Calò V, Bruno L, et al. Is BRCA1-5083del19, identified in breast cancer patients of Sicilian origin, a Calabrian founder mutation? Breast Cancer Res Treat. 2009;113:67-70.

36. Caligo MA, Ghimenti C, Cipollini G, et al. BRCA1 germline mutational spectrum in Italian families from Tuscany: a high frequency of novel mutations. Oncogene. 1996;13:1483-1488.

37. Sluiter MD, van Rensburg EJ. Large genomic rearrangements of the BRCA1 and BRCA2 genes: review of the literature and report of a novel BRCA1 mutation. Breast Cancer Res Treat. 2011;125:325-349.

38. Hansen TO, Jønson L, Albrechtsen A, Andersen MK, Ejlertsen B, Nielsen FC. Large BRCA1 and BRCA2 genomic rearrangements in Danish high risk breast-ovarian cancer families. Breast Cancer Res Treat. 2009;115:315-323.

39. Karhu R, Laurila E, Kallioniemi A, Syrjäkoski K. Large genomic BRCA2 rearrangements and male breast cancer. Cancer Detect Prev. 2006;30:530-534.

40. Woodward AM, Davis TA, Silva AG, Kirk JA, Leary JA; kConFab Investigators. Large genomic rearrangements of both BRCA2 and BRCA1 are a feature of the inherited breast/ovarian cancer phenotype in selected families. J Med Genet. 2005;42:e31.
41. Walsh T, Casadei S, Coats KH, et al. Spectrum of mutations in BRCA1, BRCA2, CHEK2, and TP53 in families at high risk of breast cancer. JAMA. 2006;295:1379-1388.

42. Wang T, Lerer I, Gueta Z, et al. A deletion/insertion mutation in the BRCA2 gene in a breast cancer family: a possible role of the Alu-polyA tail in the evolution of the deletion. Genes Chromosomes Cancer. 2001;31:91-95.

43. Tournier I, Paillerets BB, Sobol H, et al. Significant contribution of germline BRCA2 rearrangements in male breast cancer families. Cancer Res. 2004;64:8143-8147.

44. Gutiérrez-Enríquez S, de la Hoya M, Martínez-Bouzas C, et al. Screening for large rearrangements of the BRCA2 gene in Spanish families with breast/ovarian cancer. Breast Cancer Res Treat. 2007;103:103-107.

45. Meijers-Heijboer H, van den Ouweland A, Klijn J, et al. Low-penetrance susceptibility to breast cancer due to $\mathrm{CHEK} 2(*) 1100 \mathrm{delC}$ in noncarriers of BRCA1 or BRCA2 mutations. Nat Genet. 2002;3:55-59.

46. Weischer M, Bojesen SE, Ellervik C, Tybjaerg-Hansen A, Nordestgaard BG. CHEK2*1100delC genotyping for clinical assessment of breast cancer risk: meta-analyses of 26,000 patient cases and 27,000 controls. J Clin Oncol. 2008;26:542-548.

47. Neuhausen S, Dunning A, Steele L, et al. Role of CHEK2*1100delC in unselected series of non-BRCA1/2 male breast cancers. Int J Cancer. 2004; 108:477-478.

48. Ohayon T, Gal I, Baruch RG, Szabo C, Friedman E. CHEK2*1100delC and male breast cancer risk in Israel. Int J Cancer. 2004;108:479-480.

49. Syrjäkoski K, Kuukasjärvi T, Auvinen A, Kallioniemi OP. CHEK2 $1100 \mathrm{delC}$ is not a risk factor for male breast cancer population. Int $J$ Cancer. 2004;108:475-476.

50. Falchetti M, Lupi R, Rizzolo P, et al. BRCA1/BRCA2 rearrangements and CHEK2 common mutations are infrequent in Italian male breast cancer cases. Breast Cancer Res Treat. 2008;110:161-167.

51. Martinez-Bouzas C, Beristain E, Guerra I, et al. CHEK2 1100delC is present in familial breast cancer cases of the Basque Country. Breast Cancer Res Treat. 2007;103:111-113.

52. Narod SA, Lynch HT. CHEK2 mutation and hereditary breast cancer. J Clin Oncol. 2007;25:6-7.

53. Caligo MA, Agata S, Aceto G, et al. The CHEK2 c.1100delC mutation plays an irrelevant role in breast cancer predisposition in Italy. Hum Mutat. 2004;24:100-101.

54. Schutte M, Seal S, Barfoot R, et al. Breast Cancer Linkage Consortium. Variants in CHEK2 other than 1100delC do not make a major contribution to breast cancer susceptibility. Am J Hum Genet. 2003;72:1023-1028.

55. Bogdanova N, Enssen-Dubrowinskaja N, Feshchenko S, et al. Association of two mutations in the CHEK2 gene with breast cancer. Int J Cancer. 2005;116:263-266.

56. Swift M, Reitnauer PJ, Morrell D, Chase CL. Breast and other cancers in families with ataxia-telangiectasia. $N$ Engl J Med. 1987;316: 1289-1294.

57. Thompson D, Duedal S, Kirner J, et al. Cancer risks and mortality in heterozygous ATM mutation carriers. J Natl Cancer Inst. 2005;97: 813-822.

58. Renwick A, Thompson D, Seal S, et al. ATM mutations that cause ataxia-telangiectasia are breast cancer susceptibility alleles. Nat Genet. 2006;38:873-875.

59. Levy-Lahad E. Fanconi anemia and breast cancer susceptibility meet again. Nat Genet. 2010;42:368-369.

60. Rahman N, Seal S, Thompson D, et al. PALB2, which encodes a BRCA2-interacting protein, is a breast cancer susceptibility gene. Nat Genet. 2007;39:165-167.

61. Tischkowitz M, Xia B, Sabbaghian N, et al. Analysis of PALB2/ FANCN-associated breast cancer families. Proc Natl Acad Sci U S A. 2007;104:6788-6793.

62. Cao AY, Huang J, Hu Z, et al. The prevalence of PALB2 germline mutations in BRCA1/BRCA2 negative Chinese women with early onset breast cancer or affected relatives. Breast Cancer Res Treat. 2009; 114:457-462. 
63. Heikkinen T, Kärkkäinen H, Aaltonen K, et al. The breast cancer susceptibility mutation PALB2 1592delT is associated with an aggressive tumor phenotype. Clin Cancer Res. 2009;15:3214-3222.

64. Papi L, Putignano AL, Congregati C, et al. A PALB2 germline mutation associated with hereditary breast cancer in Italy. Fam Cancer. 2010;9: 181-185.

65. Dansonka-Mieszkowska A, Kluska A, Moes J, et al. A novel germline PALB2 deletion in Polish breast and ovarian cancer patients. BMC Med Genet. 2010;11:20.

66. Sluiter M, Mew S, van Rensburg EJ. PALB2 sequence variants in young South African breast cancer patients. Fam Cancer. 2009;8:347-353.

67. García MJ, Fernández V, Osorio A, et al. Analysis of FANCB and FANCN/PALB2 Fanconi anemia genes in BRCA1/2-negative Spanish breast cancer families. Breast Cancer Res Treat. 2009;113: 545-551.

68. Balia C, Sensi E, Lombardi G, Roncella M, Bevilacqua G, Caligo MA. PALB2: a novel inactivating mutation in a Italian breast cancer family. Fam Cancer. 2010;9:531-536.

69. Ding YC, Steele L, Chu LH, et al. Germline mutations in PALB2 in African-American breast cancer cases. Breast Cancer Res Treat. 2011; 126:227-230.

70. Erkko H, Xia B, Nikkilä J, et al. A recurrent mutation in PALB2 in Finnish cancer families. Nature. 2007;446:316-319.

71. Foulkes WD, Ghadirian P, Akbari MR, et al. Identification of a novel truncating PALB2 mutation and analysis of its contribution to earlyonset breast cancer in French-Canadian women. Breast Cancer Res. 2007;9:R83.

72. Sauty de Chalon A, Teo Z, Park DJ, et al. Are PALB2 mutations associated with increased risk of male breast cancer? Breast Cancer Res Treat. 2010;121:253-255.

73. Silvestri V, Rizzolo P, Zanna I, et al. PALB2 mutations in male breast cancer: a population-based study in Central Italy. Breast Cancer Res Treat. 2010;122:299-301.

74. Adank MA, van Mil SE, Gille JJ, Waisfisz Q, Meijers-Heijboer H. PALB2 analysis in BRCA2-like families. Breast Cancer Res Treat. 2011;127:357-362.

75. Ding YC, Steele L, Kuan CJ, Greilac S, Neuhausen SL. Mutations in BRCA2 and PALB2 in male breast cancer cases from the United States. Breast Cancer Res Treat. 2011;126:771-778.

76. Casadei S, Norquist BM, Walsh T, et al. Contribution to familial breast cancer of inherited mutations in the BRCA2-interacting protein PALB2. Cancer Res. 2011;71:2222-2229.

77. Seal S, Thompson D, Renwick A, et al. Truncating mutations in the Fanconi anemia J gene BRIP1 are low-penetrance breast cancer susceptibility alleles. Nat Genet. 2006;38:1239-1241.

78. Karppinen SM, Vuosku J, Heikkinen K, Allinen M, Winqvist R. No evidence of involvement of germline BACH1 mutations in Finnish breast and ovarian cancer families. Eur J Cancer. 2003;39:366-371.

79. Guénard F, Labrie Y, Ouellette G, et al. Mutational analysis of the breast cancer susceptibility gene BRIP1/BACH1/FANCJ in high-risk non-BRCA1/BRCA2 breast cancer families. J Hum Genet. 2008; 53:579-591.

80. Cao AY, Huang J, Hu Z, et al. Mutation analysis of BRIP1/BACH1 in BRCA1/BRCA2 negative Chinese women with early onset breast cancer or affected relatives. Breast Cancer Res Treat. 2009;115:51-55.

81. Lewis AG, Flanagan J, Marsh A, et al. Mutation analysis of FANCD2, BRIP1/BACH1, LMO4 and SFN in familial breast cancer. Breast Cancer Res. 2005;7:R1005-R1016.

82. De Nicolo A, Tancredi M, Lombardi G, et al. A novel breast cancerassociated BRIP1 (FANCJ/BACH1) germ-line mutation impairs protein stability and function. Clin Cancer Res. 2008;14:4672-4680.

83. Silvestri V, Rizzolo P, Falchetti M, et al. Mutation analysis of BRIP1 in male breast cancer cases: a population-based study in Central Italy. Breast Cancer Res Treat. 2011;126:539-543.

84. Meindl A, Hellebrand H, Wiek C, et al. Germline mutations in breast and ovarian cancer pedigrees establish RAD51C as a human cancer susceptibility gene. Nat Genet. 2010;42:410-414.
85. Akbari MR, Tonin P, Foulkes WD, Ghadirian P, Tischkowitz M, Narod SA. RAD51C germline mutations in breast and ovarian cancer patients. Breast Cancer Res. 2010;12:404.

86. Zheng Y, Zhang J, Hope K, Niu Q, Huo D, Olopade OI. Screening RAD51C nucleotide alterations in patients with a family history of breast and ovarian cancer. Breast Cancer Res Treat. 2010; 124:857-861.

87. Silvestri V, Rizzolo P, Falchetti M, et al. Mutation screening of RAD51C in male breast cancer patients. Breast Cancer Res. 2011; 13:404.

88. Pharoah PD, Antoniou A, Bobrow M, Zimmern RL, Easton DF, Ponder BA. Polygenic susceptibility to breast cancer and implications for prevention. Nat Genet. 2002;31:33-36.

89. Breast Cancer Association Consortium. Commonly studied singlenucleotide polymorphisms and breast cancer: results from the Breast Cancer Association Consortium. J Natl Cancer Inst. 2006; 98:1382-1396

90. Easton DF, Pooley KA, Dunning AM, et al. Genome-wide association study identifies novel breast cancer susceptibility loci. Nature. 2007; 447:1087-1093.

91. Cox A, Dunning AM, Garcia-Closas M, et al. A common coding variant in CASP8 is associated with breast cancer risk. Nat Genet. 2007; 39:352-358.

92. Stacey SN, Manolescu A, Sulem P, et al. Common variants on chromosome $5 \mathrm{p} 12$ confer susceptibility to estrogen receptor-positive breast cancer. Nat Genet. 2008;40:703-706.

93. Thomas G, Jacobs KB, Kraft P, et al. A multistage genome-wide association study in breast cancer identifies two new risk alleles at 1p11.2 and 14q24.1 (RAD51L1). Nat Genet. 2009;41:579-584.

94. Dunning AM, Healey CS, Baynes C, et al. Association of ESR1 gene tagging SNPs with breast cancer risk. Hum Mol Genet. 2009; 18:1131-1139.

95. Turnbull C, Ahmed S, Morrison J, et al. Genome-wide association study identifies five new breast cancer susceptibility loci. Nat Genet. 2010;42:504-507.

96. Fletcher O, Houlston RS. Architecture of inherited susceptibility to common cancer. Nat Rev Cancer. 2010;10:353-361.

97. Antoniou AC, Spurdle AB, Sinilnikova OM, et al. Common breast cancer-predisposition alleles are associated with breast cancer risk in BRCA1 and BRCA2 mutation carriers. Am J Hum Genet. 2008; 82:937-948

98. Wasserman NF, Aneas I, Nobrega MA. An 8q24 gene desert variant associated with prostate cancer risk confers differential in vivo activity to a MYC enhancer. Genome Res. 2010;20:1191-1197.

99. Ghoussaini M, Song H, Koessler T, et al. Multiple loci with different cancer specificities within the 8q24 gene desert. J Natl Cancer Inst. 2008;100:962-966.

100. Wokołorczyk D, Lubiński J, Narod SA, Cybulski C. Genetic heterogeneity of $8 \mathrm{q} 24$ region in susceptibility to cancer. J Natl Cancer Inst. 2009;101:278-279.

101. Wokolorczyk D, Gliniewicz B, Sikorski A, et al. A range of cancers is associated with the rs6983267 marker on chromosome 8. Cancer Res. 2008;68:9982-9986.

102. Bonifaci N, Górski B, Masojć B, et al. Exploring the link between germline and somatic genetic alterations in breast carcinogenesis. PLoS One. 2010;5:e14078.

103. Stacey SN, Manolescu A, Sulem P, et al. Common variants on chromosomes $2 \mathrm{q} 35$ and $16 \mathrm{q} 12$ confer susceptibility to estrogen receptorpositive breast cancer. Nat Genet. 2007;39:865-869.

104. Garcia-Closas M, Chanock S. Genetic susceptibility loci for breast cancer by estrogen receptor status. Clin Cancer Res. 2008;14: 8000-8009.

105. Wood LD, Parsons DW, Jones S, et al. The genomic landscapes of human breast and colorectal cancers. Science. 2007;318: 1108-1113.

106. Greenman C, Stephens P, Smith R, et al. Patterns of somatic mutation in human cancer genomes. Nature. 2007;446:153-158. 
107. Bachman KE, Argani P, Samuels Y, et al. The PIK3CA gene is mutated with high frequency in human breast cancers. Cancer Biol Ther. 2004;3:772-775.

108. Saal LH, Holm K, Maurer M, et al. PIK3CA mutations correlate with hormone receptors, node metastasis, and ERBB2, and are mutually exclusive with PTEN loss in human breast carcinoma. Cancer Res. 2005;65:2554-2559.

109. Li SY, Rong M, Grieu F, Iacopetta B. PIK3CA mutations in breast cancer are associated with poor outcome. Breast Cancer Res Treat. 2006;96:91-95.

110. Maruyama N, Miyoshi Y, Taguchi T, Tamaki Y, Monden M, Noguchi S. Clinicopathologic analysis of breast cancers with PIK3CA mutations in Japanese women. Clin Cancer Res. 2007;13(2 Pt 1):408-414.

111. Jong YJ, Li LH, Tsou MH, et al. Chromosomal comparative genomic hybridization abnormalities in early- and late-onset human breast cancers: correlation with disease progression and TP53 mutations. Cancer Genet Cytogenet. 2004;148:55-65.

112. Langerød A, Zhao H, Borgan $\varnothing$, et al. TP53 mutation status and gene expression profiles are powerful prognostic markers of breast cancer. Breast Cancer Res. 2007;9:R30.

113. Holstege H, Joosse SA, van Oostrom CT, Nederlof PM, de Vries A, Jonkers J. High incidence of protein-truncating TP53 mutations in BRCA1-related breast cancer. Cancer Res. 2009;69:3625-3633.

114. Al-Kuraya K, Schraml P, Torhorst J, et al. Prognostic relevance of gene amplifications and coamplifications in breast cancer. Cancer Res. 2004;64:8534-8540.

115. Sunami E, Shinozaki M, Sim MS, et al. Estrogen receptor and HER2/ neu status affect epigenetic differences of tumor-related genes in primary breast tumors. Breast Cancer Res. 2008;10:R46.

116. Nana-Sinkam SP, Croce CM. MicroRNAs as therapeutic targets in cancer. Transl Res. 2011;157:216-225.

117. Lerebours F, Lidereau R. Molecular alterations in sporadic breast cancer. Crit Rev Oncol Hematol. 2002;44:121-141.

118. Bell DW. Our changing view of the genomic landscape of cancer. J Pathol. 2010;220:231-243.

119. Kan Z, Jaiswal BS, Stinson J, et al. Diverse somatic mutation patterns and pathway alterations in human cancers. Nature. 2010;466: 869-873.

120. Arnold JM, Choong DY, Thompson ER, et al. Frequent somatic mutations of GATA3 in non-BRCA1/BRCA2 familial breast tumors, but not in BRCA1-, BRCA2- or sporadic breast tumors. Breast Cancer Res Treat. 2010;119:491-496.

121. Campbell IG, Russell SE, Choong DY, et al. Mutation of the PIK3CA gene in ovarian and breast cancer. Cancer Res. 2004;64: 7678-7681.

122. Buttitta F, Felicioni L, Barassi F, et al. PIK3CA mutation and histological type in breast carcinoma: high frequency of mutations in lobular carcinoma. J Pathol. 2006;208:350-355.

123. Dunlap J, Le C, Shukla A, et al. Phosphatidylinositol-3-kinase and AKT1 mutations occur early in breast carcinoma. Breast Cancer Res Treat. 2010;120:409-418.

124. Benvenuti S, Frattini M, Arena S, et al. PIK3CA cancer mutations display gender and tissue specificity patterns. Hum Mutat. 2008; 29:284-288.

125. Bader AG, Kang S, Zhao L, Vogt PK. Oncogenic PI3K deregulates transcription and translation. Nat Rev Cancer. 2005;5:921-929.

126. Børresen-Dale AL. TP53 and breast cancer. Hum Mutat. 2003;21: 292-300.

127. Olivier M, Hainaut P. TP53 mutation patterns in breast cancers: searching for clues of environmental carcinogenesis. Semin Cancer Biol. 2001;11:353-360.

128. McKinzie PB, Delongchamp RR, Heflich RH, Parsons BL. Prospects for applying genotypic selection of somatic oncomutation to chemical risk assessment. Mutat Res. 2001;489: 47-78.

129. Pietsch EC, Humbey O, Murphy ME. Polymorphisms in the p53 pathway. Oncogene. 2006;25:1602-1611.
130. Damin AP, Frazzon AP, Damin DC, et al. Evidence for an association of TP53 codon 72 polymorphism with breast cancer risk. Cancer Detect Prev. 2006;30:523-529.

131. Khadang B, Fattahi MJ, Talei A, Dehaghani AS, Ghaderi A. Polymorphism of TP53 codon 72 showed no association with breast cancer in Iranian women. Cancer Genet Cytogenet. 2007;173:38-42.

132. Osorio A, Martínez-Delgado B, Pollán M, et al. A haplotype containing the p53 polymorphisms Ins16bp and Arg72Pro modifies cancer risk in BRCA2 mutation carriers. Hum Mutat. 2006;27:242-248.

133. Martin AM, Kanetsky PA, Amirimani B, et al. Germline TP53 mutations in breast cancer families with multiple primary cancers: is TP53 a modifier of BRCA1? J Med Genet. 2003;40:e34.

134. Venables JP, Klinck R, Bramard A, et al. Identification of alternative splicing markers for breast cancer. Cancer Res. 2008;68: 9525-9531.

135. Watson PM, Watson DK. Alternative splicing in prostate and breast cancer. The Open Cancer Journal. 2010;3:62-76.

136. Orban TI, Olah E. Emerging roles of BRCA1 alternative splicing. Mol Pathol. 2003;56:191-197.

137. Castiglioni F, Tagliabue E, Campiglio M, Pupa SM, Balsari A, Ménard S. Role of exon-16-deleted HER2 in breast carcinomas. Endocr Relat Cancer. 2006;13:221-232.

138. André F, Michiels S, Dessen P, et al. Exonic expression profiling of breast cancer and benign lesions: a retrospective analysis. Lancet Oncol. 2009; 10:381-390.

139. LaVoie HA, DeSimone DC, Gillio-Meina C, Hui YY. Cloning and characterization of porcine ovarian estrogen receptor $\beta$ isoforms. Biol Reprod. 2002;66:616-623.

140. Kwong KY, Hung M. A novel splice variant of HER2 with increased transformation activity. Mol Carcinog. 1998;23:62-68.

141. Rodriguez C, Hughes-Davies L, Vallès H, et al. Amplification of the BRCA2 pathway gene EMSY in sporadic breast cancer is related to negative outcome. Clin Cancer Res. 2004;10:5785-5791.

142. Ciampa A, Xu B, Ayata G, et al. HER-2 status in breast cancer: correlation of gene amplification by FISH with immunohistochemistry expression using advanced cellular imaging system. Appl Immunohistochem Mol Morphol. 2006;14:132-137.

143. Vanden Bempt I, Drijkoningen M, De Wolf-Peeters C. The complexity of genotypic alterations underlying HER2-positive breast cancer: an explanation for its clinical heterogeneity. Curr Opin Oncol. 2007;19: $552-557$.

144. Ross JS, Fletcher JA. The HER-2/neu oncogene in breast cancer: prognostic factor, predictive factor, and target for therapy. Stem Cells. 1998; 16:413-428.

145. Francis G, Beadle G, Thomas S, Mengersen K, Stein S. Evaluation of oestrogen and progesterone receptor status in HER-2 positive breast carcinomas and correlation with outcome. Pathology. 2006;38: 391-398.

146. Stratford AL, Fry CJ, Desilets C, et al. Y-box binding protein-1 serine 102 is a downstream target of p90 ribosomal S6 kinase in basal-like breast cancer cells. Breast Cancer Res. 2008;10:R99.

147. Tsutsui S, Ohno S, Murakami S, Hachitanda Y, Oda S. Prognostic value of epidermal growth factor receptor (EGFR) and its relationship to the estrogen receptor status in 1029 patients with breast cancer. Breast Cancer Res Treat. 2002;71:67-75.

148. Uberall I, Kolár Z, Trojanec R, Berkovcová J, Hajdúch M. The status and role of ErbB receptors in human cancer. Exp Mol Pathol. 2008;84:79-89.

149. Toyama T, Yamashita H, Kondo N, et al. Frequently increased epidermal growth factor receptor (EGFR) copy numbers and decreased BRCA1 mRNA expression in Japanese triple-negative breast cancers. BMC Cancer. 2008;8:309.

150. Chen Y. MYC in breast tumor progression. Expert Rev Anticancer Ther. 2008;8:1689-1698.

151. Holst F, Stahl PR, Ruiz C, et al. Estrogen receptor alpha (ESR1) gene amplification is frequent in breast cancer. Nat Genet. 2007;39: 655-660. 
152. Roy PG, Thompson AM. Cyclin D1 and breast cancer. Breast. 2006;15: $718-727$.

153. Courjal F, Louason G, Speiser P, Katsaros D, Zeillinger R, Theillet C. Cyclin gene amplification and overexpression in breast and ovarian cancers: evidence for the selection of cyclin D1 in breast and cyclin E in ovarian tumors. Int J Cancer. 1996;69:247-253.

154. Bärlund M, Monni O, Kononen J, et al. Multiple genes at 17q23 undergo amplification and overexpression in breast cancer. Cancer Res. 2000;60:5340-5344.

155. Kirkegaard T, Nielsen KV, Jensen LB, et al. Genetic alterations of CCND1 and EMSY in breast cancers. Histopathology. 2008;52: 698-705

156. Tan DS, Marchiò C, Reis-Filho JS. Hereditary breast cancer: from molecular pathology to tailored therapies. J Clin Pathol. 2008;61: 1073-1082.

157. Tommasi S, Mangia A, Iannelli G, et al. Gene copy number variation in male breast cancer by aCGH. Anal Cell Pathol (Amst). 2010;33: 113-119.

158. Fonseca RR, Tomás AR, André S, Soares J. Evaluation of ERBB2 gene status and chromosome 17 anomalies in male breast cancer. Am J Surg Pathol. 2006;30:1292-1298.

159. Bärlund M, Kuukasjärvi T, Syrjäkoski K, Auvinen A, Kallioniemi A. Frequent amplification and overexpression of CCND1 in male breast cancer. Int J Cancer. 2004;111:968-971.

160. Dworkin AM, Huang THM, Ewart Toland A. Epigenetic alterations in the breast: implications for breast cancer detection, prognosis and treatment. Semin Cancer Biol. 2009;19:165-171.

161. Jovanovica J, Anders Rønnebergb J, Tost J, Kristensena V. The epigenetics of breast cancer. Mol Oncol. 2010;4:242-254.

162. Lapidus R, Ferguson AT, Ottaviano YL, et al. Methylation of estrogen and progesterone receptor gene $50 \mathrm{CpG}$ islands correlates with lack of estrogen and progesterone receptor gene expression in breast tumors. Clin Cancer Res. 1996;2:805-810.

163. Bae YK, Brown A, Garrett E, et al. Hypermethylation in histologically distinct classes of breast cancer. Clin Cancer Res. 2004;10: 5998-6005.

164. Fackler MJ, McVeigh M, Evron E, et al. DNA methylation of RASSF1A, HIN-1, RAR-beta, Cyclin D2 and Twist in in situ and invasive lobular breast carcinoma. Cancer. 2003;107:970-975.
165. Li S, Rong M, Iacopetta B. DNA hypermethylation in breast cancer and its association with clinicopathological features. Cancer Lett. 2006;237:272-280.

166. Feng W, Shen L, Wen S, et al. Correlation between CpG methylation profiles and hormone receptor status in breast cancers. Breast Cancer Res. 2007;9:R57.

167. Parrella P, Poeta ML, Gallo AP, et al. Nonrandom distribution of aberrant promoter methylation of cancer-related genes in sporadic breast tumors. Clin Cancer Res. 2004;10:5349-5354.

168. Widschwendter M, Siegmund KD, Muller HM, et al. Association of breast cancer DNA methylation profiles with hormone receptor status and response to tamoxifen. Cancer Res. 2004;64:3807-3813.

169. Shenouda SK, Alahari SK. MicroRNA function in cancer: oncogene or a tumor suppressor? Cancer Metastasis Rev. 2009;28:369-378.

170. Iorio MV, Ferracin M, Liu CG, et al. MicroRNA gene expression deregulation in human breast cancer. Cancer Res. 2005;65:7065-7070.

171. Shi M, Guo N. MicroRNA expression and its implications for the diagnosis and therapeutic strategies of breast cancer. Cancer Treat Rev. 2009;35:328-334.

172. Png KJ, Yoshida M, Zhang XH, et al. MicroRNA-335 inhibits tumor reinitiation and is silenced through genetic and epigenetic mechanisms in human breast cancer. Genes Dev. 2011;25:226-231.

173. Fassan M, Baffa R, Palazzo JP, et al. MicroRNA expression profiling of male breast cancer. Breast Cancer Res. 2009;11:R58.

174. Lehmann U, Streichert T, Otto B, et al. Identification of differentially expressed microRNAs in human male breast cancer. BMC Cancer. 2010;10:109.

175. Sempere LF, Christensen M, Silahtaroglu A, et al. Altered microRNA expression confined to specific epithelial cell subpopulations in breast cancer. Cancer Res. 2007;67:11612-11620.

176. Yan LX, Huang XF, Shao Q, et al. MicroRNA miR-21 overexpression in human breast cancer is associated with advanced clinical stage, lymph node metastasis and patient poor prognosis. $R N A$. 2008;14: 2348-2360.

177. Ottini L, Capalbo C, Rizzolo P, et al. HER2-positive male breast cancer: an update. Breast Cancer: Targets and Therapy. 2010;2:45-58.

178. Saxena R, Dwivedi A. ErbB family receptor inhibitors as therapeutic agents in breast cancer: current status and future clinical perspective. Med Res Rev. October 25, 2010. [Epub ahead of print].
The Application of Clinical Genetics

\section{Publish your work in this journal}

The Application of Clinical Genetics is an international, peer-reviewed open access journal that welcomes laboratory and clinical findings in the field of human genetics. Specific topics include: Population genetics; Functional genetics; Natural history of genetic disease; Management of genetic disease; Mechanisms of genetic disease; Counselling and

\section{Dovepress}

ethical issues; Animal models; Pharmacogenetics; Prenatal diagnosis; Dysmorphology. The manuscript management system is completely online and includes a very quick and fair peer-review system, which is all easy to use. Visit http://www.dovepress.com/testimonials.php to read real quotes from published authors. 